\title{
Макєঠovıкá
}

Tóp. 3 (1956)

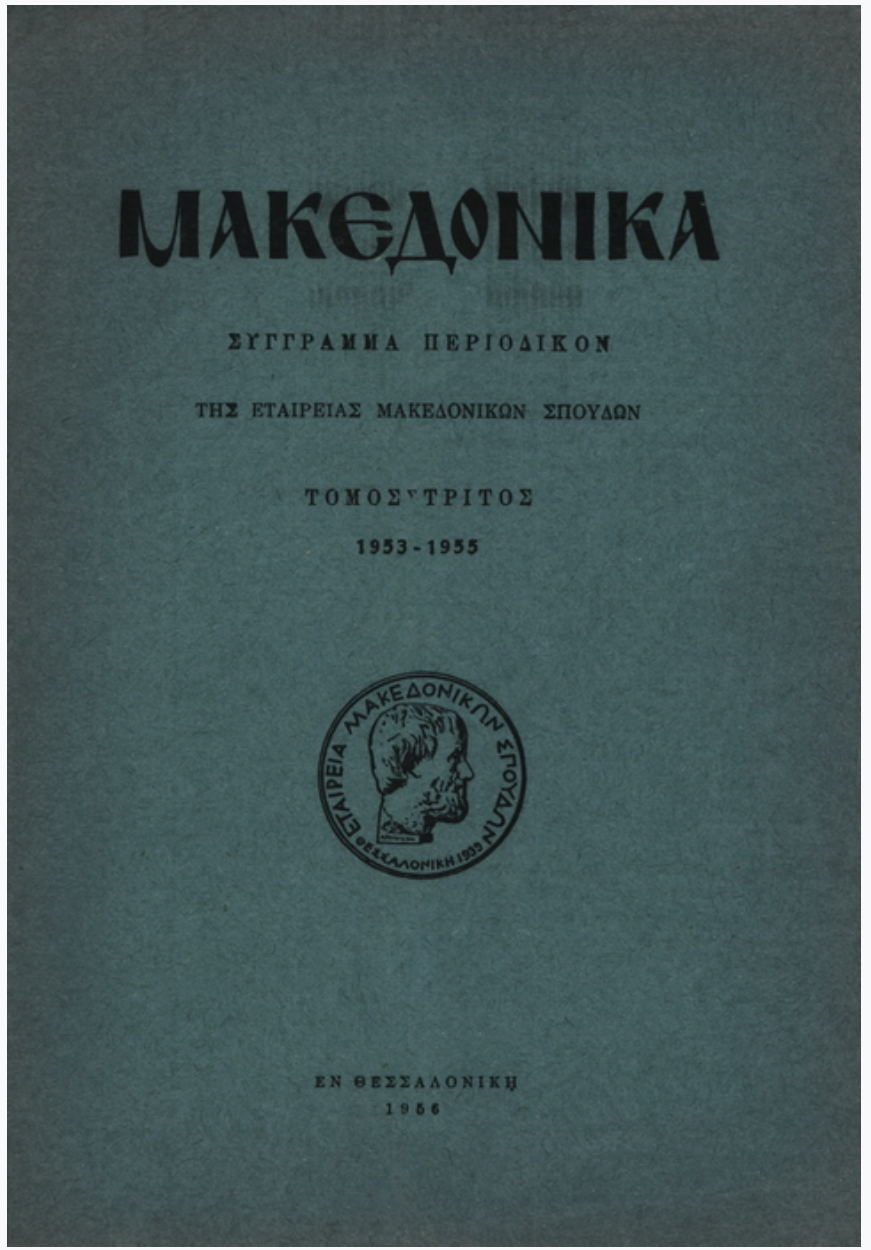

\section{G. B. Zotiades, The Macedonian controversy}

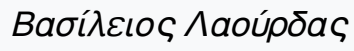

doi: $\underline{10.12681 / \text { makedonika.1123 }}$

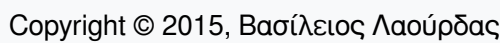

\section{@ $\oplus \Theta \odot$}

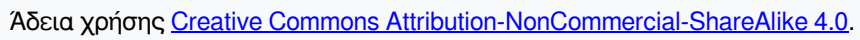

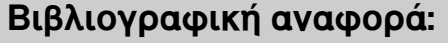

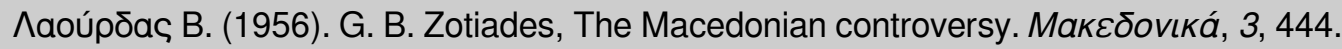

https://doi.org/10.12681/makedonika.1123 


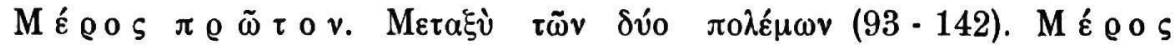

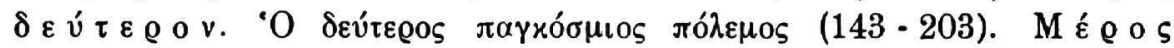

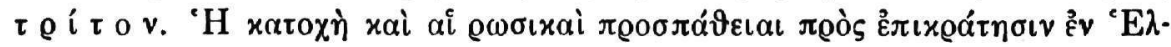

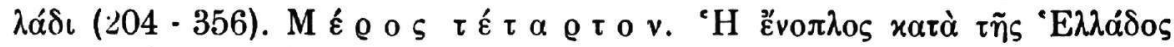

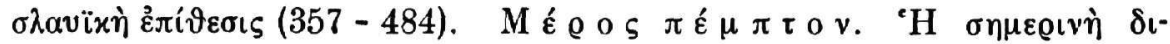

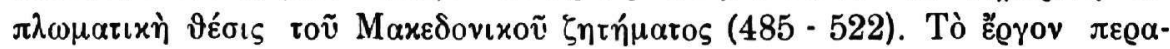

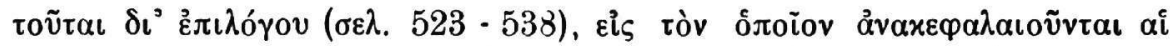

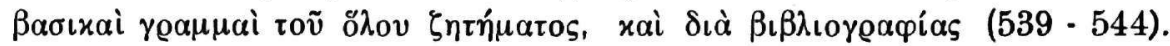

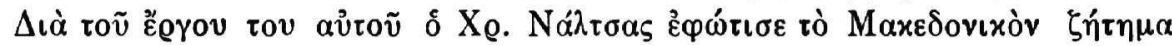

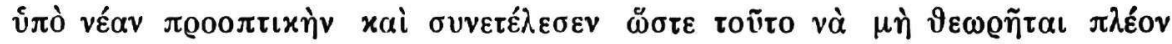

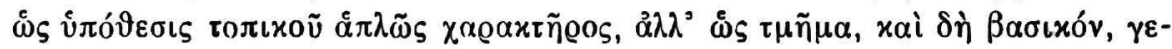

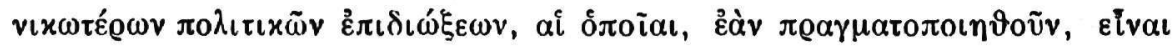

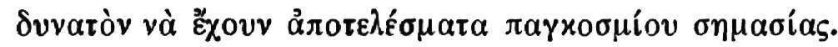

BAI. NAOYPAAI

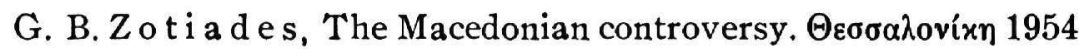

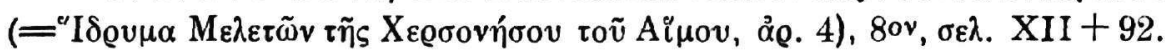

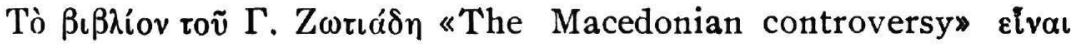

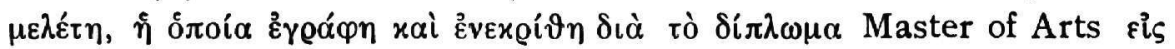

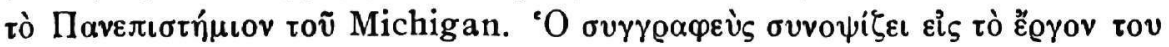

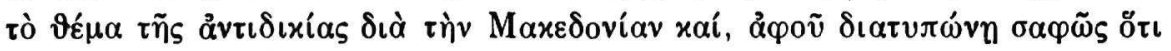

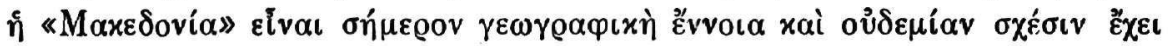

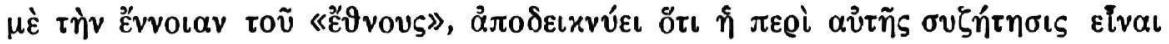

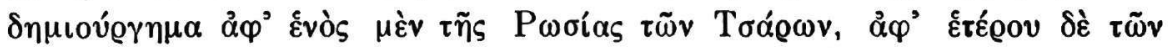

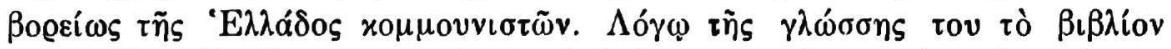

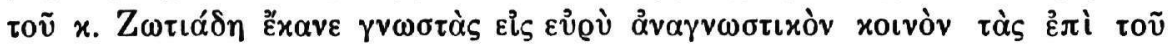

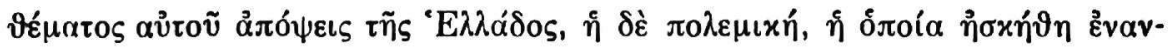

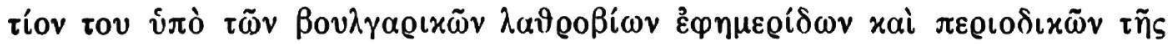

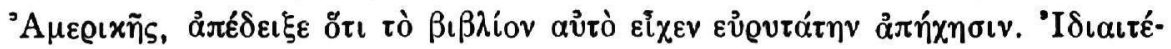

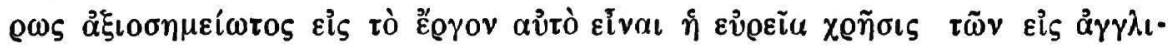

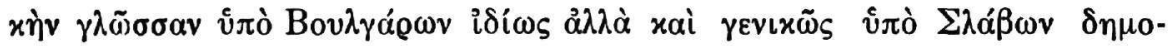

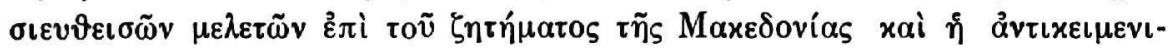

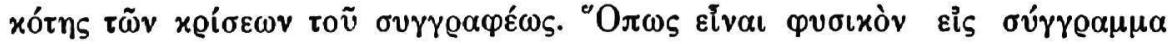

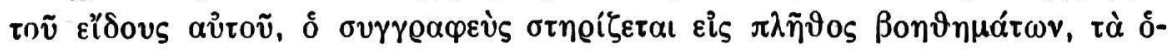

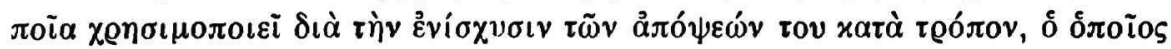

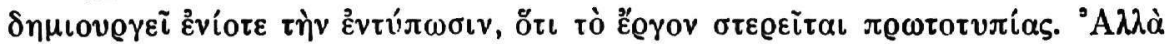

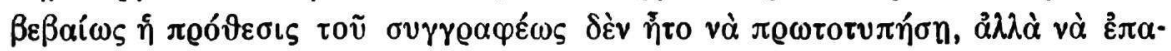

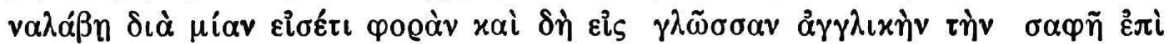

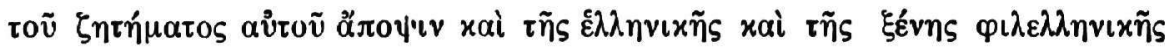

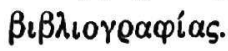

BAI. NAOYPAAI 